The current movement towards local pay bargaining will make the centralised structure designed to deal with central pay bargaining an anachronism. If the BMA feels threatened by this the way forward is within its own mechanisms and not by attempting to engulf medical directors. If medical directors have any ability to influence change on the wider front it is by giving advice within the system and leaving the political machinations to the BMA, whose task it rightfully is.

We regard ourselves as at least as well intentioned as the chairman of the Central Consultants and Specialists Committee and not a wit less aware. The committee has its own important role. Ours is new and different and needs to be entirely separate.

MERVYN ROSENBERG Chairman, Medical Directors of Wales

Wrexham Maelor Hospital NHS Trust,

Clwyd LL13 7TD

1 Beecham L. New committee will represent clinical and medical directors. $B M F$ 1994;309:1376. (19 November.)

\section{BMA's reply}

EDITOR,-Mervyn Rosenberg's letter betrays some important misunderstandings about the role of the BMA and its craft committees. Certainly a major role of the craft committees is to negotiate terms and conditions of service for their constituents, but this is by no means their only function. The Central Consultants and Specialists Committee, for example, represents the views and interests of senior hospital doctors on a much wider range of issues that have nothing to do with terms of employment. These include medical staffing, NHS funding and the internal market, complaints procedures, information technology, and management structures. The committee is conscious that its policies on these issues will be truly representative of the views of the body of senior hospital doctors only if they are formed with input from clinical and medical directors, who are an integral and increasingly influential part of that body.

There has been mounting pressure from BMA members who are clinical and medical directors and who wish to see a mechanism to ensure their input to their professional association. The Central Consultants and Specialists Committee has responded to this by setting up the new subcommittee, which has attracted considerable interest and support. We acknowledge that there may be difficulties in the relationship between the new subcommittee and the Central Consultants and Specialists Committee and the BMA in its trade union role, and of course clinical and medical directors will continue to influence matters from outside the BMA. We do not wish, however, to seem to deny the existence of different points of view within the profession by cutting off this group of members from their professional organisation. After all, what group is likely to make a more important contribution to the BMA's attempts to "adapt to the cultural alterations currently taking place regarding health care delivery in general"?

Rosenberg is right to point out that the new subcommittee, as part of the representative structure of the Central Consultants and Specialists Committee, covers only those clinical and medical directors who are senior hospital doctors (the overwhelming majority). We are now looking carefully at aspects of our representative structure that may no longer reflect the changed NHS, and we may need to make changes in the longer term; the Central Consultants and Specialists Committee, however, has rightly acted to put a structure in place for its own constituents in the meantime.

\section{Getting started as a medical manager}

EDITOR,-In their article on getting started as a medical manager J F Riordan and Jenny Simpson comment on several important issues facing senior clinicians involved in management.' We believe, however, that articles on management for doctors repeatedly omit one factor.

Learning by doing and getting to know your workforce are established methods in management training. In most major companies managers are required to spend a period of their training working with their workforce at every level. "Getting to know your colleagues" is the phrase applied to this exercise. It seems to be accepted among the NHS management, however, that consultants are the only people worth talking to. Junior doctors rarely see managers, let alone think that they have any experience of the problems associated with caring for patients. An interesting paradox thus arises: on the one hand, managers speak of teamwork, communication, learning by doing, etc and chastise the medical profession for not adopting these perceived virtues; on the other hand, they avoid contact with most of the workforce. Riordan and Simpson's article mentions how Dr B enjoyed working with the bright, newly recruited young managers; it seems that medical juniors, who may well have trained for a considerably longer time, are not thought of with such affection among medical management. This is insulting.

The time to expose doctors to new skills and ideas must surely be while they are still young and adaptable to change. NHS managers should attempt to apply the principles expounded in their "management speak" when dealing with junior medical staff. Truly integrated management promotes staff morale and corporate identity, which leads to increased loyalty and higher productivity. If we worked together from an early stage it would reduce the culture shock for both parties and allow a more gradual transition into management at the consultant level. Who knows, doctors might even learn to communicate and work as a team just as well as the NHS management.

P J DREW

Academic Surgical Unit, Research fellow

University of Hull Postgraduate Medical School, Castle Hill Hospital,

Cottingham,

North Humberside HU16 5JQ

A GILBERT

Asda Stores,

Swanley,

Kent BR8 7UN

1 Riordan JF, Simpson J. Getting started as a medical manager $B M F$ 1994;309:1563-5. (10 December.)

\section{Authors' reply}

EDITOR,-In our experience, the managerial attitude to junior doctors described by P J Drew and A Gilbert is still common. Fortunately, however, it is giving way in many hospitals to an understanding by managers of the important roles of junior doctors and other professionals and a willingness to work with them. Many management trainees work well with their junior medical colleagues with mutual benefit, although several have commented to us that they find it difficult to work effectively with junior doctors unless they have already received cooperation from their consultants.

As we stated in our article, we believe that clinical audit is an important entry point into the management process for many junior doctors. It could also be used by clinicians to encourage interaction between management trainees and junior doctors, although in our experience it is not commonly so used at present. Management training courses on which junior doctors meet and work with members of other professions and junior managers are also effective in promoting the growth of teamwork with its attendant benefits for all.

We are confident that with the increasing use of these and other methods, progress will continue in breaking down the "tribal" barriers within our hospitals, with benefits to both staff and patients. JF RIORDAN Central Middlesex Hospital NHS Trust, London NW10 7NS xecutive medical director

British Association of Medical Managers,

J SIMPSON

British Association

Cheadle,

Cheshire SK8 2NY

\section{Health promotion in general practice}

\section{Any beneficial effect was lost in background statistical noise}

EDITOR,-We are confused about the methods that M E Cupples and A McKnight used in their study of health promotion in general practice. ${ }^{1}$ The sole criterion for inclusion in the study was angina, and the protocol seems not to have excluded those patients with previous myocardial infarcts, in whom low concentrations of cholesterol have been shown to be beneficial. ${ }^{2}$ The criterion chosen to indicate a successful outcome seems arbitrary and excessive: a more than $50 \%$ reduction in the incidence of angina in two years. Yet, even given this limitation, the death rate was halved in the treatment group in two years. The causes of death are not stated in the report, though cardiac diseases should be strongly suspected.

The study showed an influence on eating habits, yet no extra effect was seen on body mass index, which suggests that general overnutrition (mean body mass index of 27) and its associated risks were not affected by health education. The authors admit the lack of effect of education about smoking; they did not, however, validate their measurements of smoking for all patients by using serum cotinine concentrations while admitting that $6 \%$ of patients who claimed to be non-smokers lied, allowing errors of underrecording to be missed. It is interesting that the treatment group exercised more or claimed more exercise and an unaltered number of angina attacks while at the same time increasing their use of prophylactic treatment. The possibility of self prophylaxis by the treatment group before exercise seems to have been neglected. Again, exercise tolerance was not validated independently in the study. The feeling of reduced restriction, while not affecting overall rates of angina, suggests the possibility of a placebo effect. We question the assertion that the reduction in cholesterol concentration was significant as a $2 \cdot 4 \%$ fall $(P=0.003)$ is equivalent to a $5 \%$ reduction in risk in the general population, according to data gathered in the multiple risk factor intervention trial. ${ }^{3}$ Larger reductions might be expected in groups at higher risk.

The most interesting contrast, however, is between this study and the Stanford coronary risk intervention project, which showed, at four years, significant reductions in cholesterol and triglyceride concentrations, weight, and rate of progression of narrowing of the coronary arteries while also showing an increase in high density lipoprotein concentrations and exercise capacity with a halving of the rate of admission to hospital. ${ }^{4}$ This implies that the benefit to patients of reducing risk factors becomes unequivocal only at four years. This study lasted only two years, and any beneficial 
effects of intervention were lost in the background statistical noise. This study should not preclude a full integrated approach to the management of risk factors, including health education, dietary intervention, and drug treatment as it is necessary for the long term health of patients.

Charing Cross and Westminster Medical School,

Chelsea and Westminster Hospital,

London SW10 9NH

T M REYNOLDS

Burton Hospitals,

Burton on Trent DE13 0RB

1 Cupples ME, McKnight A. Randomised controlled trial of health promotion in general practice for patients at high cardiovascular risk. $B M \mathcal{F}$ 1994;309:993-6. (15 October.)

2 Betteridge DJ, Dodson PM, Durrington PN, Hughes EA, Lake MF, Nicholls DP, et al. Management of hyperlipidaemia: guidelines of the British Hyperlipidaemia Association. Post grad Med f 1993:69:359-69.

3 Neaton JD, Wentworth D, MRFIT triallists. Serum cholesterol, blood pressure, cigarette smoking and death from coronary heart disease. Arch Intern Med 1992;152:56-64.

4 Haskell WL, Alderman EL, Fair JM, Maron DJ, Mackey SF, Superko HR, et al. Effects of intensive multiple risk factor reduction on coronary atherosclerosis and clinical cardiac events in men and women with coronary artery disease: the Stanford coronary risk intervention project (SCRIP). Circulation 1994;89:975-90.

\section{Focus on modification of risk factors and patients' perception of lifestyle}

EdrTor,-M E Cupples and A McKnight conclude that personal health education of patients with ischaemic heart disease had no significant effect on objective cardiovascular risk factors, although some beneficial effects on exercise and diet were seen. ${ }^{1}$ In a preliminary survey of hospital inpatients recovering from an acute myocardial infarction we have come to broadly similar conclusions.

Using a structured questionnaire, we surveyed 23 patients ( 19 men, four women; mean age 63.5 years (range 37-81) within five years of admission with an acute myocardial infarction and three months later, after a cardiac rehabilitation programme. We assessed their overall awareness of their condition and their self reported profile of

Risk factors and intended changes in lifestyle among 23 patients surveyed within five days of acute myocardial infarction and three months later

Baseline Interview at $\chi^{2}$ Test an interview 3 months $P$ value

\begin{tabular}{|c|c|c|c|}
\hline \multicolumn{4}{|c|}{ Risk factors } \\
\hline \multicolumn{4}{|l|}{ Smoking: } \\
\hline Yes & 8 & 2 & $\chi^{2}=4 \cdot 60$ \\
\hline No & 15 & 21 & $\widehat{P}=0.03$ \\
\hline \multicolumn{4}{|l|}{ Stressful lifestyle: } \\
\hline Yes & 13 & 5 & $\chi^{2}=5 \cdot 84$ \\
\hline No & 10 & 18 & $\hat{\mathrm{P}}=0.02$ \\
\hline \multicolumn{4}{|l|}{ Healthy diet: } \\
\hline Yes & 19 & 21 & \\
\hline No & 4 & 2 & NS \\
\hline \multicolumn{4}{|l|}{ Exercise habit: } \\
\hline Never & 4 & 2 & \\
\hline Occasionally & 6 & 5 & \\
\hline Moderately often & 6 & 7 & \\
\hline Frequently & 7 & 9 & NS \\
\hline \multicolumn{4}{|c|}{ Intended changes in lifestyle } \\
\hline \multicolumn{4}{|c|}{ Eating a healthy diet: } \\
\hline No change & 12 & 5 & $\chi^{2}=4 \cdot 57$ \\
\hline Considerable change & 11 & 18 & $\mathrm{P}=0.03$ \\
\hline \multicolumn{4}{|l|}{ More exercise: } \\
\hline No change & 10 & 9 & \\
\hline Considerable change & 13 & 14 & NS \\
\hline \multicolumn{4}{|l|}{ Career change: } \\
\hline No change & 15 & 12 & \\
\hline Considerable change & 8 & 11 & NS \\
\hline \multicolumn{4}{|l|}{ Driving ability: } \\
\hline No change & 19 & 16 & \\
\hline Considerable change & 4 & 7 & NS \\
\hline \multicolumn{4}{|l|}{ Family life: } \\
\hline No change & 18 & 15 & \\
\hline Considerable change & 5 & 8 & NS \\
\hline \multicolumn{4}{|l|}{ Social life: } \\
\hline No change & 17 & 17 & \\
\hline Considerable change & 6 & 6 & NS \\
\hline
\end{tabular}

risk factors and intended modifications to their lifestyle immediately after the infarct and at three months' follow up. Sixteen patients considered that they were more aware of their condition at follow up; six, however, reported that they were neither more nor less aware of their condition, and 10 considered that too little had been explained to them about their treatment, despite the rehabilitation programme.

There was a significant reduction in the prevalence of smoking and in stressful lifestyles after the infarction. Diet and the amount of regular exercise, however, were not significantly different (table). Intended changes in lifestyle also differed when patients were interviewed immediately after infarction and at three months' follow up. In particular, attitudes towards eating a healthy diet changed significantly $(P<0.05)$. There was, however, no significant change in intended exercise routine and the patients' perception of their career or employment, family life, driving ability, or social life (table).

Our patients, who were educated about cardiovascular risk factors and underwent a risk factor modification programme after an acute myocardial infarction, reported an increased awareness of their condition. Changes in risk factors remained limited, although the prevalence of smoking and a stressful lifestyle fell, and the rehabilitation programme seemed to have only a limited effect on the patients' perception of their career, family life, driving ability, and social life. To become more effective the current programmed approach to cardiac rehabilitation after myocardial infarction may need to place more emphasis on modification of risk factors and on the patients' perception of lifestyle.

GREGORY Y H LIP
Research fellow
RICHARD BALASUBRAMANIAM
Medical student
ANDREW MAURICE
Medical student
GARETH BEEVERS
Professor of medicine

University of Birmingham

City Hospital,

Birmingham B18 7QH

1 Cupples ME, McKnight A. Randomised controlled trial of health promotion in general practice at high cardiovascular risk. $B M F$ 1994;309:993-6. (15 October.)

\section{Travel prophylaxis}

EdrTor,-Pierre van Damme and colleagues and E Walker support the findings of our study that high risk travellers should be selectively immunised, but they disagree about other issues. The aim of our study was to provide a framework in which policy related to travel prophylaxis could be explored in the context of the NHS.

While acknowledging that underreporting occurs, we used a correction factor of $50 \%$. This factor includes adjustment for diseases with short incubation periods, such as malaria and typhoid, which may well present abroad. In the case of hepatitis $A$, the incidence in British residents is similar to that used in other studies, ${ }^{23}$ and we believe that it is realistic. Had we used a lower estimate of the prevalence of hepatitis A antibody, this would have implied a larger body of susceptible travellers for the same number of cases, as defined by laboratory and clinical reports (a higher proportion were children), ${ }^{2}$ which lowers the incidence of disease. A lower incidence $(0.032 \%)$ would represent 91 fewer cases avoided, reducing the costs of avoided illness by $31 \%$, and with the same costs of prophylaxis the cost-benefit ratio increases to 8.3 . Use of the Swiss incidence in travellers $(0 \cdot 3 \%)$ would imply a cost-benefit ratio for hepatitis A vaccine as large as $2 \cdot 7$ and a ratio for human normal immunoglobulin of 1 . Allowances were made for unrecorded and multiple doses. Doses and not phials were used.

Use of incidences specific for destinations would undoubtedly enhance the model and help target prophylaxis. We are finalising such data for publication, using rates specific for destinations by risk groups.

We share the desire to improve the quality of published economic evaluations. The economic evaluation used in this study was couched in the framework of cost-benefit analysis and included a nested cost-effectiveness study of alternative regimens. The evaluation of benefits in monetary terms is a problem that haunts all cost-benefit analyses. In this study, apart from the willingness to pay (taken as an approximation of value of life), we measured benefits as costs avoided. ${ }^{4}$ The measurement of willingness to pay suggested by Martin E Backhouse-aspects of which we intend to explore-may not provide robust estimates in this area of infection control. Unfortunately, the individualistic basis of willingness to pay is found wanting in situations that have complex collective implications. ${ }^{56}$

We did not imply, as Walker suggested, that travellers should not receive immunoprophylaxis; we critically examined NHS policies that subsidise certain prophylaxis for travellers, which may be an inefficient way to spend resources in a cash strapped health service. Consultant physician in tropical and travel medicin

\section{Hospital for Tropical Diseases Travel Clinic,}

London NW1 OPE

JA ROBERTS Senior lecturer

Health Services Research Unit,

London School of Hygiene and Tropical Medicine, London WC1T 7HT

1 Travel prophylaxis [letters]. $B M \mathcal{F}$ 1995;310:401-2. (11 February.)

2 Jefferson T, Behrens RH, Demicheli V. Should British soldiers be vaccinated against hepatitis $A$ ? An economic analysis. Vaccine 1994;12:1379-84.

3 Braddick MR. Travel-associated hepatitis A. I Public Health Med 1992;14:342-3.

4 Rice DP. Cost of illness studies: fact or fiction? Lancet 1994, 344:1519-20. (3 December.)

5 Mishan EJ, ed. Cost benefit analysis. London: Unwin University Books, 1992:24.

6 Layard R, Glaiser S. Cost benefit analysis. Cambridge: Cambridge University Press, 1994:21.

\section{Aircraft cabin pressure and parkinsonian symptoms}

EDrToR,-Jeremy Brown's observation that we should question why decreased air pressure may improve parkinsonian symptoms is appropriate, but his statement that oxygen concentration in aircraft cabins ranges from $15 \cdot 2 \%$ to $17 \cdot 6 \%$ is incorrect. The cabin atmosphere obeys the physical gas laws, and Dalton's law of partial pressures ensures that the oxygen concentration is a constant $21 \%$. At $2440 \mathrm{~m}$ altitude the partial pressure of oxygen is $21 \%$ of $76 \mathrm{kPa}$-that is, 16 $\mathrm{kPa}$ - compared with $21 \mathrm{kPa}$ at sea level.

British Airways Health Services,

MICHAEL BAGSHAW

PO Box 10, Heathrow Airport,

Hounslow,

Middlesex TW6 9JA

1 Brown J. Aircraft cabin pressure and parkinsonian symptoms. $B M 7$ 1994;309:1516. (3 December.)

Campbell RD, Bagshaw M. Human performance and limitations in aviation. Oxford: Blackwell Scientific, 1991.

\section{Out of hours visits}

EDITOR,-In his editorial on home visits out of hours Brian Hurwitz points out that "no studies have documented a difference in medical outcome between night visits performed by general practitioners and those performed by deputies, though 